\title{
A CONEXÃO ENTRE CINEMA E EDUCAÇÃO: POR UMA PEDAGOGIA DAS AFECÇÕES
}

\author{
Hugo Souza Garcia Ramos ${ }^{1}$ \\ Alexsandro Rodrigues ${ }^{2}$
}

\begin{abstract}
O cinema talvez seja a mais mágica de todas as artes e que melhor expressa a vida vivida. Como atividade que exprime sensibilidade e reflexão, condicionada por seu tempo e pela técnica que a torna possível [...], o cinema tem como uma de suas funções reconhecer e interpretar a experiência humana. Mesmo quando não se apresentam como narrativas, os filmes sempre formulam uma visão de mundo, e é neste nível que ocorrem suas indagações e tentativas de resposta. (DUARTE, 2010, p. 45).
\end{abstract}

Para Duarte (2010), existe no cinema uma dimensão pedagógica que é desempenhada de diversas formas sobre a sociedade. Essa inter-relação do cinema com a educação é histórica. No Brasil, desde a década de 1930, os educadores, em especial os escolanovistas, enfatizavam a importância do cinema na educação. Sua apropriação no ambiente educacional se tornou um importante instrumento didático para o processo de ensino-aprendizagem de diversas disciplinas, por exemplo, Ciências, Geografia e História. No entanto, o que ocorria, de fato, era de "adequar a linguagem cinematográfica ao formato escolar para a veiculação de conhecimentos legítimos" (ALEGRIA, 2005, p. 09).

Diante desse contexto, questionamos: Como o cinema está inserido no universo escolar? Existem realmente fronteiras e hierarquização da linguagem escrita em detrimento da linguagem audiovisual no currículo escolar? Somente é possível utilizar o cinema como material pedagógico e/ou ilustrativo nas salas de aula? É papel da escola o ensino das linguagens audiovisuais? O cinema é só diversão e entretenimento? Como pensar as narrativas audiovisuais em si mesmas como conhecimento?

\section{Afinal, o que educação tem a ver com o cinema?}

É fato que vivemos numa era digital com imagens por todos os cantos, brechas e espaços. Nessa cultura contemporânea hipervisualisada (MARTINS, 2010), a qualquer momento e em qualquer lugar, é possível com o aparelho celular produzir uma filmagem em que nós mesmos somos os produtores, editores, marketeiros, enfim, realizamos todo o processo. Para tanto, as redes sociais se fizeram de extrema importância. Facebook e sobretudo Youtube permitiram uma revolução na forma de produção, em especial no momento da divulgação de vídeos em geral e no acesso à linguagem audiovisual.

Os cotidianos das escolas também são inundados pelos desejos fílmicos da nossa cultura de imagem, pois eles já se encontram presentes junto aos alunos/as, independente da escola trabalhar e desenvolver atividades relacionadas ou não. Soares (2009, p. 250) nos lembra de que as diferentes formas de tecnologias de comunicação.

\footnotetext{
${ }^{1}$ Mestrando do Programa de Pós-Graduação em Psicologia Institucional da Universidade Federal do Espírito Santo e integrante do Grupo de Estudos e Pesquisas em Sexualidades (GEPS).E-mail: hugo-sgramos@hotmail.com

${ }^{2}$ Professor do Programa de Pós Graduação de Psicologia Institucional da Universidade Federal do Espírito Santo (UFES). Coordenador do Grupo de Estudos e Pesquisas em Sexualidades (GEPS). E-mail: xela_alex@bol.com.br
} 
estão lá, fazem parte do cotidiano escolar e da tessitura dos currículos, independente de sua presença física e das operações de uso e suas diversas lógicas, porque fazem parte das redes e de saberesfazeres e sentidos nas quais estão enredados os praticantes da escola e que são tecidas por sujeitos em comunicação.

Apesar da consequente facilidade de acesso e uso das narrativas audiovisuais nas práticas pedagógicas, muitos de nós, professores, fazemos uso dos filmes apenas como recurso didático atraente e "lúdico" para o saber que está contido nele, um material ilustrativo e secundário. Como se fosse um aditivo tecnológico para incrementar um processo educativo de ciências já consolidadas, por exemplo, História, Geografia, Biologia etc. Não conseguimos ainda pensar a arte do cinema, por si só, como capaz de proporcionar novas relações de espaço, tempo e sujeitos.

Destacamos, ainda, que na educação infantil a exibição de filme é utilizada, em muitos momentos, como uma atividade para preencher um tempo livre - seja de lazer e/ou relaxamento. Sem direcionamento pedagógico algum, nem mesmo como recurso ilustrativo com uma participação secundária.

Pensamos na companhia de Duarte (2009), que tal prática pode estar relacionada com a presença em nossa cultura da ideia de que o cinema é só diversão e entretenimento. Além disso, a relação com os produtos audiovisuais (mais especificamente: cinema e tevê), é vista de modo negativo na nossa sociedade, como se esses contribuíssem para o desinteresse nas atividades direcionadas pela linguagem escrita.

Por vezes, o texto fílmico, ainda, tem sido usado como forma de normatização e moralização da vida. Ele adentra a escola e os espaços educativos, muitas vezes percorrendo o caminho de uma moral disciplinadora. É importante ressaltar que não existem textos, filmes, imagens e linguagens neutras. Ainda que de forma despretensiosa, não podemos esquecer como nos ensina Ellsworth, que existe uma relação entre as práticas sociais e os agenciamentos de modos de vida forjados na obra cinematográfica. Ou seja, as imagens de um filme interpelam, agenciam e possuem um endereçamento.

Para que um filme funcione para um determinado público, para que ele chegue a fazer sentido para uma espectadora, ou para que ele a faça rir, para que a faça torcer por um personagem (...) sentir-se feliz ao final - a espectadora deve entrar em uma relação particular com a história e o sistema de imagem do filme. (ELLSWORTH, 2001, p. 14).

Temos, assim, três questões importantes para discutir: primeiro a concepção de que o cinema é compreendido, no senso comum, apenas como diversão e entretenimento; e segundo é a dicotomia entre a linguagem audiovisual e escrita. Terceiro, a utilização do cinema para difusão de práticas disciplinadoras e moralizadoras. No imperativo da ação cinema e educação, os professores ainda insistem na produção de provas pedagógicas. Raras são as vezes que não se pede no término da exibição de um filme, para que as crianças produzam desenhos e escritas sobre. Parece que a aula com cinema só é válida se acontecer um registro.

O cinema é uma importante fonte de conhecimento, de formação e informação, "configurando-se, assim, como uma prática eminentemente pedagógica" (DUARTE, 2009, p. 67). Ademais, de acordo com Anita Leandro (2001), existe uma pedagogia intrínseca na imagem pelo fato dela pensar e provocar pensamento.

Dessa maneira, os filmes não podem ser compreendidos somente como entretenimento, mas como adverte Fabris (2008, p. 119), ao mesmo tempo em que divertem, eles desenvolvem uma pedagogia, ensinam modos de vida. Por meio dos Estudos Culturais, é possível visualizar os filmes para além do entretenimento, como um sistema de significações, como produtores de sentidos. 
A outra questão que precisa ser discutida que perpassa as práticas pedagógicas e a nossa sociedade é a respeito das supostas fronteiras entre linguagem escrita e linguagem audiovisual. Como se o livro fizesse pensar, enquanto o filme apenas divertisse. Ambos possuem valor, uso e importância. Trazemos Flusser (apud MEDEIROS, VIEIRA E VASCONCELOS, 2014, p. 3), para nos ajudar a pensar esta relação entre texto e imagem:

Ao inventar a escrita, o homem se afastou ainda mais do mundo concreto quando, efetivamente, pretendia dele se aproximar. A escrita surge de um passo para aquém das imagens e não de um passo em direção ao mundo. Os textos não significam o mundo diretamente, mas através de imagens rasgadas. Os conceitos não significam fenômenos, significam ideias. Decifrar textos é descobrir as imagens significadas pelos conceitos. A função dos textos é explicar imagens, a dos conceitos é analisar cenas. Em outros termos: a escrita é metacódigo da imagem.

A relação da escrita está imbricada com o pensamento imagético e ao decodificar os textos o homem se depara com imagens. Ou seja, ambas são produtoras de conhecimento. Não é possível pensar uma hierarquização e dicotomias entre o texto escrito e a imagem. As imagens são capazes de suscitar da mesma forma que o texto escrito todo um processo cognitivo.

Assim, os filmes não podem continuar a serem vistos como atividade secundária ou material meramente ilustrativo das práticas pedagógicas de nós professores/as, é preciso que haja um planejamento antes de exibir: elaborar um roteiro de discussão e definir os objetivos claramente.

Além disso, é necessário que os docentes tenham acesso à teoria e história do cinema, da cinematografia, ou seja, é imperativo um investimento de uma formação relacionada ao cinema. Do mesmo modo que fazemos para adquirir a leitura e a escrita, há a necessidade de oferecer recursos adequados para a aquisição do domínio da linguagem audiovisual.

A última questão se refere da utilização do cinema a um lugar de moral e de verdade conformada com estruturas de poder e de manutenção que visam o governo de corpos e de uma população. Porém, nós pensamos e desejamos o cinema com a educação em uma direção contrária: como máquina de guerra, como espaço-tempo criativo, de problematização e afirmação de uma vida. Não nos conformamos com as práticas que reiteram a lógica da contenção e da manutenção das tradicionais estruturas de poder pelas vias pedagógicas.

O cinema a partir dessa perspectiva como lugar de poder que legitima identidades sociais pode ser analisado pelo viés do gênero e sexualidade. Torna-se, assim, um importante instrumento para produzir corpos generificados e sexualizados conformados com a lógica heternormativa. Pelos contos de fadas presentes nos filmes e desenhos animados, aprendemos desde muito cedo a sermos menino ou menina numa coerência corpo, gênero e sexualidade. Em outras palavras, busca-se produzir uma relação linear-causal entre: sexo [pênis/vagina] > gênero [masculino/feminino] > desejo [se sentir atraído sexualmente] > identidades sexuais.

No entanto, é preciso problematizar esta concepção de que as identidades sexuais são biologicamente definidas, formadas por um núcleo fixo, natural; um modelo que se baseia num imperativo que determina um único modelo como socialmente aceitável. O que se busca, é implantar padrões em detrimento das inúmeras formas de se viver com o outro e com os prazeres do corpo. Em suma, os filmes podem exercer pedagogias da sexualidade sobre suas plateias (LOURO, 2008).

Até agora foram problematizadas algumas questões da articulação do cinema com a educação. Neste artigo propomos pensar esta intrínseca e vital relação através da seguinte 
proposição ${ }^{3}$ : o cinema como um dispositivo formativo. Para tanto, recorremos ao conceito foucaultiano de dispositivo, ou seja,

um conjunto heterogêneo, comportando discursos, instituições, conjuntos arquiteturais, decisões regulamentares, leis, medidas administrativas, enunciados científicos, proposições filosóficas, morais, enfim: o dito como o não dito (...) o dispositivo, nele mesmo, é a rede que se pode estabelecer entre estes elementos. (FOUCAULT, 2000, p. 244).

Dessa maneira, o dispositivo, constituído por práticas discursivas e não-discursivas, reúne instâncias de poder, saber e (de produção de modos de) subjetivação. No que se refere ao cinema como um dispositivo educativo, destacamos o processo de subjetivação, ensinando modos de ser e de agir. Nesse sentido, falamos de educação como conceituada pela Lei de Diretrizes e Bases da Educação Nacional, em que educação envolve todo e qualquer processo formativo:

Art. $1^{\circ}$. A educação abrange os processos formativos que se desenvolvem na vida familiar, na convivência humana, no trabalho, nas instituições de ensino e pesquisa, nos movimentos sociais e organizações da sociedade civil e nas manifestações culturais. (BRASIL, 1996).

Existe, portanto, uma produção pedagógica do sujeito na qual destacamos a importância de uma formação estética- ética- política conforme a perspectiva de Félix Guatarri:

estético porque criação permanente, subvertendo a pretensa unidade do mundo capitalista; ético porque potência ativa que surge na imanência das práticas para coordenar a vida e escolher a forma de vivê-la, e político porque implica a escolha de modos de mundo que se quer viver. (apud BARROS, 2000, p. 41).

Essa perspectiva não é somente uma atitude frente a uma formação, é também uma atitude de vida. Instaura-se a possibilidade de o cinema ser uma ferramenta que possibilita colocar nossas vidas como obra de arte (FERRARI, 2012). Precisamos no apoiar no movimento de criação e, não nos restringirmos ao plano da moral - que prescreve um modelo ideal de agir, ser e estar no mundo, naturalizando, assim, as diferentes formas de vida.

\section{Por uma pedagogia das afecções}

Como pensar o cinema como intempestivo? Em que medida é possível aproximar as experiências estéticas das práticas pedagógicas? Como pensar uma política do sensível no processo de ensino-aprendizagem? E a articulação da formação do sujeito com a experiência estética na escola?

Talvez, se nos aproximarmos das questões que Cynthia Farina (2005) defende em sua tese "Arte, Corpo e Subjetividade - Estética da formação e pedagogia das afecções", tenhamos uma possibilidade de começo para essas indagações.

A respeito da formação estética, a autora afirma que essa se dá através da diversidade de imagens, performances e discursos que inundam nosso cotidiano. Isso ocorre através de como

\footnotetext{
${ }^{3}$ Proposições de acordo com o significado proposto por Latour (2008, p. 45), e que possui três elementos fundamentais: “a) denota uma obstinação(posição), que b) não tem uma autoridade definitiva (é apenas uma proposição) e c) pode aceitar negociar-se a si própria para formar uma com-posição sem perder a solidez”.
} 
nos afetam e de como reagimos a isso. A nossa experiência estética se configura pela ação das imagens sobre nossas maneiras de ver e viver as coisas, e das nossas maneiras de narrá-las.

Para Farina, seriam as afecções que poderiam articular a experiência estética e a pedagogia. A essa ideia ela chamou de pedagogia das afecções. Escreve a autora:

Uma pedagogia das afecções não estabeleceria modelos pedagógicos como tampouco moralizaria formas de comportamento, mas se proporia como um marco de ação e pensamento que partisse da prática de sujeitos concretos para a produção de estratégias de formação, intervenção e participação na realidade, cuja validez se daria nas maneiras de tratar com situações específicas. Esse marco de atividade se basearia em estratégias de participação na realidade inspiradas em algumas práticas estéticas atuais, em sua consciência do funcionamento do institucional, em suas maneiras de dá-lo a ver, de deslizar-se ou de instalar-se sobre ele como parasita, para improvisar formas de ação coerentes com a ética e a política que tentam desdobrar (2007, p. 779).

Com esta ideia é possível abrir para produção de novas formas de sentir e outras formas de pensar. As imagens podem afetar os sujeitos e os colocarem em processo de problematização. Desse modo, vive-se uma experiência estética com o cinema, quando produz uma trans-formação a partir do que desestabiliza, que nos provoca a pensar.

Nesse sentido, seria uma pedagogia que parte e se dirige às experiências que o sujeito vive no corpo. Para Latour (2008) o corpo é um lugar em que ocorre uma aprendizagem de ser afetado, um aprender a ser sensível. O corpo disponível as experimentações, articulado com as diferentes entidades humanas e não humanas presentes em cena que ele, ao mesmo tempo, afeta e é afetado. É preciso procurar provocar o deslocamento do corpo em meio à circulação, variação e transformação de afetos.

Deleuze (2002:74) a partir da teoria da ética em Spinosa, afirma que há "uma correspondência entre as afecções do corpo e as ideias no espírito, correspondência pela qual essas ideias representam aquela afecções." Diante disso, para um corpo ser afetado, isso passa pela existência de outro corpo externo ao seu, e isso não depende do sujeito. Há uma relação intrínseca entre corpo e mundo. O sujeito não compreende a causa, percebe somente o efeito de imediato. E tais afecções compõem relações que podem aumentar nossa potência de agir (alegria), ora podem comprometer ou inibir nossas relações (tristeza) (DELEUZE, 2002).

Uma pedagogia das afecções está centrada nas afecções que ocorrem no sujeito provocando deslocamentos. É no encontro entre os sujeitos e as imagens que será possível acionar o mundo virtual do campo de forças. De algo que ainda não possui forma, que não está dado e que vai ganhar expressão. De acordo com Suely Rolnik (2003), conhecer o mundo como um desenho de uma forma está relacionado com a percepção. A percepção do outro traz sua existência traduzida em representações, sejam elas visuais, auditivas etc. Percebemos que se trata de apreender a realidade como uma representação, como algo já pré-existente que simplesmente apreendemos.

Por outro lado, conhecer o mundo como campo de forças está relacionado às sensações, uma sensibilidade engendrada a partir do encontro de corpos. Neles percorrem ondas nervosas e que são afetados por forças do mundo. É a partir de um corpo vibrátil (ROLNIK, 2014), sensível às afecções - produzidas nos encontros - que se acessa este outro plano da realidade junto com seus efeitos e reações. As imagens afetam o corpo vibrátil, fazendo com que ele se mova, retirando-se do lugar.

Assim, apostamos numa pedagogia das afecções que visa à experimentação das relações entre o estético e a trans-formação do sujeito, concebendo o cinema como um estímulo para 
processos de criação e invenção. Somente cria-se algo novo quando se rompe com um território existente e se acessa o plano virtual da realidade.

\section{Referências}

ALEGRIA, João. Um sonho, um belo sonho: considerações sobre a gênese das relações entre a educação e cinema no Brasil. Revista Diálogo Educacional, Curitiba, v. 5, n. 15, jan./jun. 2005.

BARROS, Maria Elizabeth Barros de. Procurando outros paradigmas para a educação. Educação \& Sociedade, v. 21, n. 72, p. 32-42, agosto 2000.

BRASIL (1996). Ministério da Educação. Lei de Diretrizes e Bases da Educação Nacional, n. 9.394, de 20 de dez. 1996.

DELEUZE, Gilles. Espinosa: filosofia prática. São Paulo: Escuta, 2002.

DUARTE, Rosália. Cinema e educação. $3^{\text {a }}$ ed. Belo horizonte: Autêntica Editora, 2009.

ELLSWORTH, Elizabeth. Modos de endereçamento: uma coisa de cinema; uma coisa de educação também. In: SILVA, Tomaz T. (Org.). Nunca fomos humanos. Belo Horizonte: Autêntica, 2001.

FABRIS, Elín Henn. Cinema e educação: um caminho metodológico. Educação \& Realidade, Porto Alegre, v. 33, n. 1, p. 117-134, jan./jun. 2008.

FARINA, Cynthia. Arte, cuerpo e subjetividade. Estética de la formación y pedagogia de las afecciones, 2005. Tese - Programa de Docotorado del Departamento de teoria e Historia de la educación, Facultad de Pedagogia, Universidad de Barcelona, Espanha.

Arte, corpo e subjetividade. Experiência estética e pedagogia. In: Encontro Nacional da Associação Nacional de Pesquisadores de Artes Plásticas, 2007, Florianópolis. Anais eletrônicos... Disponível em: 〈http://www.anpap.org.br/anais/2007/2007/artigos/078.pdf>. Acesso em: 10/12/2015.

FERRARI, Anderson. Cultura visual e homossexualidades na constituição de "novas" infâncias e "novos" docentes. Revista Brasileira de Educação, Rio de Janeiro, v. 17, n. 49, p. 107-120, jan./abr. 2012.

FOUCAULT, Michel. Vigiar e punir. Rio de Janeiro: Vozes, 2000.

LATOUR, Bruno. Como falar do corpo? A dimensão normativa dos estudos sobre a ciência. In: NUNES, João Arriscado; ROQUE, Ricardo (Org.). Objetos impuros: Experiências em Estudos sobre a Ciência. Porto: Afrontamento, 2008. p. 39-61.

LEANDRO, ANITA. Da imagem pedagógica à pedagogia da imagem. Comunicação $e$ educação, São Paulo, n. 21, p. 29-36, maio/agosto, 2001. 
LOURO, Guacira Lopes. Cinema e Sexualidade. Educação \& Realidade, Porto Alegre, v. 33, n. 1, p. 81-98, jan./jun. 2008.

MARTINS, Raimundo. Hipervisualização e territorialização: questões da Cultura Visual. Educação \& Linguagem, São Paulo, v. 13, n.22, p. 19-31, jul./dez., 2010.

MEDEIROS, Cristiano Sant'Anna; VIERIA, Ana Letícia; VASCONCELOS, Suellen. As narrativas audiovisuais como potencializadoras das discussões sobre gênero e sexualidade. In: Seminário Nacional de Educação, Diversidade Sexual e Direitos Humanos, 3, 2014, Vitória. Anais eletrônicos... Disponível em: 〈http://www.gepsexualidades.com.br/resources/anais/4/1404610017〉. Acesso em: 19 de Março de 2015.

ROLNIK, Suely. Cartografia sentimental: transformações contemporâneas do desejo. $2^{\text {a }}$ edição, Porto Alegre: Sulina, 2014.

ROLNIK, Suely. Fale com ele ou como tratar o corpo vibrátil em coma. Conferência apresentada no Simpósio Corpo, Arte e Clínica, 2003, Instituto de Psicologia, Programa de PósGraduação em Psicologia Social e Institucional da UFRGS. Porto Alegre.

SOARES, Maria da Conceição Silva. Currículos: redes cotidianas de conhecimentos e sentidos tecidas por sujeitos em comunicação. 2009. Tese (Doutorado) - Universidade Federal do Espírito Santo, Centro de Educação. 